\title{
Healthy effect of different proportions of marine $\omega-3$ PUFAs EPA and DHA supplementation in Wistar rats: lipidomic biomarkers of oxidative stress and inflammation
}

\author{
Authors \\ Gabriel Dasilva ${ }^{\text {ab*, Manuel Pazos }}{ }^{\mathrm{a}}$, Eduardo García-Egido ${ }^{\mathrm{a}}$, J.M. Gallardo ${ }^{\mathrm{a}}$, Isaac \\ Rodríguez $^{\mathrm{b}}$, Rafael Cela ${ }^{\mathrm{b}}$ Isabel Medina ${ }^{\mathrm{a}}$. \\ ${ }^{a}$ Instituto de Investigaciones Marinas, Consejo Superior de Investigaciones Científicas \\ (IIM-CSIC), E-36208 Vigo, Galicia, Spain \\ ${ }^{b}$ Department of Analytical Chemistry, Nutrition and Bromatology and Research \\ Institute for Food Analysis (I.I.A.A.), University of Santiago de Compostela, E-15782 \\ Santiago de Compostela, Galicia, Spain \\ ${ }^{*}$ Corresponding author. Instituto de Investigaciones marinas, c/Eduardo Cabello 6, \\ 36208, Vigo, SpainTel. +34986231930; fax: +34986292762. E-mail address: \\ gabrieldasilva@iim.csic.es (Gabriel Dasilva)
}

\begin{abstract}
Dietary intervention with $\omega-3$ marine fatty acids may potentially modulate inflammation and oxidative stress markers related with CVD, metabolic syndrome, and cancer. The aim of this study was to evaluate whether different proportions of $\omega-3$ EPA and DHA intake provoke a modulation of the production of lipid mediators and then, an influence on different indexes of inflammation and oxidative stress in a controlled dietary animal experiment using Wistar rats. For such scope, a lipidomic SPE-LC-ESI-MS/MS approach previously developed was applied to determine lipid mediators profile in plasma samples. The effect of $\omega-3$ fatty acids associated to different ratios EPA:DHA was compared with the effect exerted by $\omega-3$ ALA supplementation from linseed oil and $\omega-6$ LA from soybean oil. CRP showed a tendency to greater inflammatory status in all $\omega-3$ fed animals. Interestingly, ratios 1:1 and 2:1 EPA:DHA evidenced a noteworthy healthy effect generating a less oxidative environment and modulating LOX and COX activities towards a decrease in the production of pro-inflammatory ARA eicosanoids and oxidative stress biomarkers from EPA and DHA. In addition, the ability of 1:1 and 2:1 fish oil diets to reduce lipid mediator levels was in concurrence with the protective effect exerted by decreasing inflammatory markers as $\omega-6 / \omega-3$ ratio in plasma and membranes. It was also highlighted the effect of a higher DHA amount in the diet reducing the healthy benefits described in terms of inflammation and oxidative stress. Results support the anti-inflammatory and anti-oxidative role of fish oils, and particularly the effect of adequate proportions EPA:DHA.
\end{abstract}

\section{Keywords}

Lipid mediators; fish oil; EPA; DHA; oxidative stress; inflammation.

\begin{abstract}
Abbreviations
ALA (linolenic acid), ARA (arachidonic acid), CAT (catalase), COX (cyclooxygenase), CRP (C-reactive protein), CVD (cardiovascular disease), DHA (docosahexaenoic acid), DPA (docosopentaenoic acid), EPA (eicosapentaenoic acid), FA (fatty acid), FFA (free fatty acid), GPX (glutathione peroxidase), HbA1c (Glycated hemoglobin), HDL (highdensity lipoprotein), LA (linoleic acid), LDL (low-density lipoprotein), LOX (lipooxygenase), MUFA (monosaturated fatty acid), ORAC (oxygen radical absorbance capacity), PUFA (polyunsaturated fatty acid), ROS (reactive oxygen specie), SFA
\end{abstract}


(saturated fatty acid), SOD (superoxide dismutase), TC (total cholesterol), TG (triglyceride), TFA (total fatty acid).

\section{Introduction}

Oxidative stress is known to trigger oxidative damage of cellular biomolecules (i.e., lipids, proteins, DNA) and has been linked to the development of inflammation and metabolic diseases [1]. Moreover, exhaustion or lack of activation of necessary inflammatory resolution mechanisms could result in subsequent organ damage, obesity, metabolic syndrome, diabetes, CVD or even cancer [2,3]. Anti-inflammatory and proinflammatory targets can alter hormonal signaling cascades to the modulation of innate immune system, via toll-like receptors and gene transcription factors resulting in the inhibition or activation of inflammatory pathways [2]. Accordingly, one of the most selective markers of cellular inflammation is the blood ratio $\omega-6 / \omega-3$, the higher ratio the greater pro-inflammatory conditions [4]. In addition, fatty acid desaturases (FAD) are important regulators of the endogenous metabolism of $\omega-6$ and $\omega-3$ PUFAs, and also regulate the desaturation of SFAs to corresponding MUFAs. High FADs activity related with the formation of oleic, palmitoleic, and arachidonic acids has been associated with obesity, hypertriacylglycerolemia, metabolic syndrome, and the risk of developing insulin resistance. In contrast, FADs associated with $\omega-3$ EPA and DHA pathways indicate insulin sensitivity, and the decrease of metabolic syndrome and CVD [5].

Moreover, $\omega-6$ and $\omega-3$ PUFAs are the main substrate of COXs, LOXs and CYP450 which produce a wide range of oxygenated lipid mediators that have been suggested as signaling molecules that may influence inflammation in a highly coordinated active process [6,7]. Specific examples include ARA eicosanoids (PGs, TXs, and LTs) [6] and IsoPs [8] which have been suggested as strong pro-inflammatory substances. The most studied: $\mathrm{PGE}_{2}, \mathrm{PGF}_{1 \alpha}, \mathrm{PGF}_{2 \alpha}, \mathrm{TXA}_{2}$ and 8 isoPGF $\mathrm{PG}_{2 \alpha}$, have been associated with inflammatory stages in studies related to hypercholesterolemia, liver cirrhosis, myocardial reperfusion, type- 2 diabetes, obesity, atherosclerosis, cancer, and CVD $[2,3,9,10]$. On the other hand, many EPA and DHA derivatives have been suggested as signaling molecules and less harmful compounds than the corresponding $\omega-6$ metabolites [11,12]. Finally, the strong anti-inflammatory and cellular protective activity of EPA and DHA resolvins and protectins has been described in studies related to CVD, dry eyes or Alzheimer [13,14]. The formation cascade of ARA, EPA and DHA metabolites is shown in the Fig. 1.

Dietary interventions have shown to modulate the specific markers of cellular inflammation and oxidative stress. Regular consumption of marine $\omega-3$ PUFAs, principally EPA and DHA, has been associated with the reduction of CVD risk factors like plasma TG, LDL, and platelet aggregation, and with the improvement of endothelial functions, and prevention of inflammatory pathways [15]. Brahmbhatt et al. have found protective effects over the intestinal inflammation of rats fed EPA:DHA (3:2) diet. The reduction of the intestinal injury was associated with the decline of oxidative stress, the up-regulation of 8 isoPGF $_{3 \alpha}$ (anti-inflammatory marker derived from EPA), and down-regulation of ARA pro-inflammatory metabolites (i.e. $\mathrm{PGE}_{2}$, $\mathrm{LTB}_{4}, \mathrm{PGD}_{2}$, Trioxilin $\mathrm{A}_{3}$ and $\mathrm{B}_{3}$ ) [16]. In a similar way, McDaniel et al. have suggested that EPA:DHA (1.3:1) supplements may alter inflammation indexes in human plasma and blister fluids. They found a decrease of $\omega-6 / \omega-3$ ratio and ARA proinflammatory metabolites (i.e., $\mathrm{LTB}_{4}, 15 \mathrm{HETE}, \mathrm{TXB}_{2}$ ) in a microenvironment of acute 
human wounds; meanwhile an increase of EPA anti-inflammatory derivates (i.e., 5-1215HEPE, $\mathrm{PGD}_{3}, \mathrm{PGE}_{3}, \mathrm{TXB}_{3}$ ) and $18 \mathrm{HEPE}$, precursor of anti-inflammatory $\mathrm{RvE}_{1}$ [17]. Similar results have been achieved by Neilson et al. in dietary experiments in rats [18].

This investigation was aimed to delve deeper into the potential anti-inflammatory and anti-oxidant effects of $\omega-3$ marine fatty acids in a controlled fed animal experiment in Wistar rats. Despite the growing evidence of health benefits associated to marine $\omega-3$ lipids, there is no agreement about a recommended daily intake in the form of DHA and EPA [19]. Therefore, we evaluated the influence that marine oils having different proportions of EPA and DHA exerted on different lipid biomarkers of oxidative stress and inflammation. Wistar female rats were fed standard diets enriched with fish oil containing three different EPA:DHA ratios (1:1, 2:1, and 1:2), and were compared with animals fed soybean and linseed oils. Soybean oil is a rich source of the $\omega-6$ LA, the dietary precursor of ARA biosynthesis; whereas, linseed oil has an elevated content of $\omega-3$ ALA, which slightly derives to EPA and DHA. The synthesis of $\omega-3$ and $\omega-6$ eicosanoid and docosanoids, the regulation of plasma and membrane FA composition, and the FADs activity were correlated with biochemical measurements and parameters of oxidative stress and inflammation (i.e. ORAC, antioxidant enzymes activity, CRP and protein carbonylation level in plasma, kidney, muscle, and liver).

\section{Materials and Methods}

\subsection{Animals and diets}

Thirteen-week old female Wistar ( $\mathrm{n}=35$, Janvier, France) rats were used as animal models. Body weight was recorded on arrival and weekly thereafter (data not shown). All the specimens were kept in an isolated room with a constantly regulated temperature an controlled humidity $\left(22 \pm 2{ }^{\circ} \mathrm{C}, 50 \pm 10 \%\right.$ humidity $)$ on a $12 \mathrm{~h}$ light/dark cycle with $a d$ libitum access to water and standard pelleted A04 chow for rodents (16\% protein, $60 \%$ carbohydrate, 3\% fat, 4\% fiber and 5\% ash; Harlan Iberica, Barcelona, Spain). Animals were randomized in five dietary groups: soybean $(n=7)$, linseed $(n=7)$, EPA:DHA 1:1 $(n=7)$, EPA:DHA 2:1 $(n=7)$, and EPA:DHA 1:2 group $(n=7)$. Each group was feed with a single weekly dose of $0,8 \mathrm{ml} / \mathrm{kg}$ of the assigned oil supplement as listed in Supplementary Material S1. Oil supplements were prepared as previously described [20]. All diets had a similar fat and energy content. The molar percentage of SFA, MUFA and PUFA was kept constant. Nonetheless, they significantly differed in the proportion of individual fatty acids. Because PUFA are easily oxidized and the oxidation products are potentially toxic, the peroxide value of the oils administered was checked periodically by the ferric thyocianate method [21]. It was below 5 meq $\mathrm{O}_{2} / \mathrm{Kg}$ of oil throughout the interventional study. After a 2-week adaptation period, the oils were administrated for 13 weeks and the experiment ended when the rats were 28 weeks old. Then, the rats were fasted overnight, anesthetized and killed by exsanguinations. Handling and killing of the animals were in full accordance with the European Union guidelines for the care and management of laboratory animals and the pertinent permission was obtained from the CSIC Subcommittee of Bioethical Issues (ref. AGL2009-12 374-C03-03).

\subsection{Fatty acid analysis of the oil supplements}

To determine the fatty acid composition of the oil supplements, $0.6 \mathrm{mg}$ of lipid were methylated according to Lepage and Roy [22]. The fatty acid nonadecanoic acid was 
used as an internal standard. The FAMEs were analyzed by gas chromatography GCFID. Results are shown in Supplementary Material S1.

\subsection{Plasma and erythrocyte sampling for FA analysis}

Blood samples were collected via cardiac puncture into polypropylene tubes containing EDTA $(1 \mathrm{mg} / \mathrm{ml})$ to remove erythrocytes, and centrifuged for $15 \mathrm{~min}$, at $4{ }^{\circ} \mathrm{C}$ and $850 \mathrm{~g}$. After that, the buffy coat was removed and the packed erythrocyte cells were washed according to the protocol developed by Sonenberg [23]. Erythrocytes were collected into clean polypropylene tubes, frozen and kept at $-80{ }^{\circ} \mathrm{C}$ until required. Then, erythrocyte free plasma was supplemented with $5 \mathrm{mM}$ PMSF (protease inhibitor) and samples were immediately stored at $-80^{\circ} \mathrm{C}$ until required.

\subsection{Extraction and analysis of plasma TFA and FFA}

Plasma samples for the analysis of TFA $(30 \mu \mathrm{L})$ and FFA $(100 \mu \mathrm{L})$ were first spiked with an internal standard of nonadecanoic acid (Larodan Fine Chemicals, MalmöSweden), and then, extracted with a dichloromethane:methanol:water mixture $(2: 2: 1$, $\mathrm{v} / \mathrm{v}$ ) according to Bligh and Dyer [24]. TFA were directly analyzed in the organic phase after dryness under a stream of nitrogen gas. Then, samples were transesterified and analyzed by gas chromatography (GC-FID, Clarus 500, Perkin-Elmer) following the method of Lepage and Roy [22]. To isolate the FFA fraction, the resulting lipid mixture obtained from the Bligh and Dyer extraction was subjected to SPE on aminopropyl cartridges $(500 \mathrm{mg}, 6 \mathrm{~mL}$, Biotage, Uppsala-Sweeden) as Kaluzny et al. described [25]. The solvent was removed under a stream of nitrogen and then subjected to transesterification and GC-FID analysis. Results are shown in Tab. 1.

\subsection{Extraction and analysis of $F A$ from erythrocyte membranes}

To study the profile of FA from the erythrocyte membranes, lyophilized erythrocyte samples $(50 \mathrm{mg})$ were extracted with the Bligh and Dyer modified procedure [26]. The organic layer was dried under nitrogen and the lipid content was gravimetrically quantified. Finally, an aliquot of organic phase containing $0.15 \mathrm{mg}$ of lipids was dried, the internal standard was spiked and transesterification and GC analysis were done as before indicated to plasma FA (Tab. 1).

\subsection{Fatty acid desaturase (FAD) indexes measurement}

Desaturase activities of dietary supplemented groups were measured using a validated methodology from the TFA data [27]. FAD indexes were calculated as product/precursor ratio for: SCD $(\mathrm{SCD}-16$ or SCD-18) $=$ [palmitoleic $(16: 1 \omega$ 7)/palmitic (16:0)] or [oleic (18:1 $\omega-9) /$ stearic (18:0)]; $\Delta 5 \mathrm{D}=$ [ARA (20:4 $\omega-6) /$ DGLA (20:3 $\omega-6)]$ and [DHA (22:6 $\omega-3) / D P A ~(22: 5 \omega-3)] ; \Delta 6 \mathrm{D}=$ [DGLA $(20: 3 \omega-6) /$ LA $(18: 2$ $\omega-6)]$; and $\Delta 5 / 6 \mathrm{D}=[\operatorname{EPA}(20: 5 \omega-3) / \operatorname{ALA}(18: 3 \omega-3)]$. Results are shown in Tab. 2.

\subsection{Solid-phase Extraction method for lipid metabolites isolation from plasma samples}

ARA, EPA and DHA oxidized lipid mediators were extracted from plasma samples by SPE following the method previously developed [28]. Briefly, samples $(90 \mu \mathrm{L})$ were diluted with $30 \%$ cold methanol (v/v), to a final volume of $1 \mathrm{~mL}$ and spiked with the internal standard 11 HETE- $d_{8}$. After centrifugation $\left(1800 \mathrm{~g}, 10 \mathrm{~min}, 4^{\circ} \mathrm{C}\right)$, samples were loaded into conditioned Oasis-HLB cartridges $(60 \mathrm{mg}, 3 \mathrm{~mL}$, Waters, MA-USA). Then,

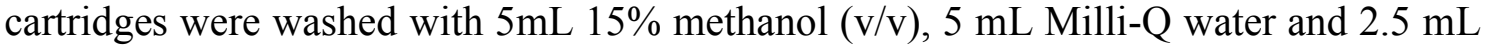
hexane in succession. After sorbent dryness, analytes were eluted with $2 \mathrm{~mL}$ methyl formate. Extracts were evaporated to dryness, re-dissolved in $30 \mu \mathrm{L}$ ethanol, and 
analyzed by LC-ESI-MS/MS. Standard solutions of lipid mediators were purchased from Cayman Chemicals (Ann Arbor, MI, USA). Methanol and Water, Optima LC-MS, were purchased from Fisher Scientific (New Jersey, USA).

\subsection{Analysis of lipid metabolites by LC-ESI-MS/MS}

Lipid mediators were quantified according to the methodology previously developed [28] and results are shown in Tab. 3. Briefly, analyses of SPE extracts were carried out on an Agilent 1260 Series (Agilent, Palo Alto, CA) coupled to a linear ion trap mass spectrometer LTQ Velos Pro with ESI (Thermo Fisher, Rockford, IL, USA). A Waters C18-Symmetry column, $150 \times 2.1 \mathrm{~mm}, 3.5 \mu \mathrm{m}$ (Milford, MA, USA) protected with a $4 \times 2 \mathrm{~mm} \mathrm{C} 18$ guard cartridge provided by Phenomenex (Torrance, CA, USA) was used. A binary eluent system of water (A) and methanol (B), both with $0.02 \%(\mathrm{v} / \mathrm{v})$ of formic acid, was used as mobile phase. The injection volume was set to $10 \mu \mathrm{L}$, ESI source operated in negative ion mode, and MS/MS conditions has been reported in detail elsewhere [28]. The quantification of target compounds was made using the most intense, or selective, ion in their product ion scan MS/MS spectra. Retention times for target compounds and individual MS/MS parameters are summarized in Supplementary Material S2.

\subsection{Statistical analysis}

Data presented are expressed as mean $\pm \mathrm{SD}$. Statistical analyses were performed by oneway analysis of variance (ANOVA) with $\mathrm{R}$ free software (version 386 3.1.0). The means were further compared by the post-hoc test Fisher least square difference (Fisher LSD) and significant differences were set at $p<0.05$. Pearson test was used in order to determine the statistical correlation between compounds and PUFAs intake.

\section{Results}

The effect of dietary interventions on eicosanoid and docosanoids synthesis, plasma and membrane fatty acid composition, and desaturases activity is described. Data obtained were correlated with previous parameters determined in the same animals and summarized in Tab. 2 [20,29]. In detail, different CVD related parameters were measured: TFA, TG, TC, HDL, LDL, HbA1c. General inflammation was measured by the concentration of CRP. Oxidative stress of animals was determined through the plasma antioxidant capacity, activity of major erythrocyte antioxidant enzymes (SOD, CAT, GPX), and by carbonylation of proteins of liver, muscle, kidney and plasma.

\subsection{Effect of dietary interventions on plasma FFA profile, and FA incorporation into tissues. Ratio $\omega-6 / \omega-3$.}

It has been observed that animals fed with enriched $\omega-3$ PUFAs (fish and linseed oils) exhibited significant higher levels of plasma $\omega-3$ FFA compared to those fed with the control $\omega-6$ soybean diet. Meanwhile, the content in plasma $\omega-6$ FFA was not modified by dietary intervention; therefore, the ratio $\omega-6 / \omega-3$ became lower with all $\omega-3$ supplements and higher by soybean treatment (Tab. 1). In addition, it is important to highlight the different fatty acid species that contributed to this $\omega-3$ enhancement. The content of EPA and DHA increased in the three fish oil diets (without significant differences between them) when compared with soybean group. Whereas, animals fed linseed diet enhanced the content of $\omega-3$ ALA when compared with soybean animals. Data were in agreement with the elevated content of EPA and DHA in fish supplements, 
while ALA was the main $\omega-3$ fatty acid in the linseed diet. The profile level of individual PUFAs showed the same tendency between the five groups: LA $>>$ ARA $>$ DHA $>$ ALA $>$ EPA (Supplementary Material S3).

The PUFAs incorporation from dietary intake into tissues is reflected in the erythrocyte membrane fatty acid composition [30]. Experimental groups under fish oil supplementation showed a significant enrichment of EPA, DPA, and DHA in the membranes, and thus, they increased the total $\omega-3$ composition when compared with control $\omega-6$ and $\omega-3$ linseed group. Moreover, fish diets revealed the lowest ARA incorporation and lowest total $\omega-6$ levels into tissues. Therefore, the inflammatory index $\omega-6 / \omega-3$ was significantly reduced by fish oil diets (without differences between 1:1, 2:1 and 1:2 groups) in comparison with linseed and soybean treatments. In addition, modulation of PUFA ratios in erythrocyte membrane by linseed supplementation was more moderated than fish diets. EPA and DPA also exhibited a significant enrichment by linseed supplementation when compared with soybean group, whereas DHA was poorly incorporated in linseed diet and it remained in the same level as soybean fed animals, significantly lower than fish ones. The ARA content was slightly reduced by linseed diet, and interestingly, the main $\omega-3$ PUFA of linseed supplement, ALA, was not significantly incorporated into the erythrocyte membranes. As a consequence, the $\omega$ 6/ $\omega-3$ ratio of linseed fed animals showed a highest value compared with fish oil groups. Results are shown in Tab. 1, and the comparison of the FA erythrocyte membrane profiles between the five groups is shown in the Supplementary Material S4: ARA $>>$ LA $>$ DHA $>$ EPA $>$ ALA.

\subsection{Effect of dietary interventions on FAD activity}

Results outlined that the studied supplements did not exert a different influence on SCD-16 [palmitoleic/palmitic], SCD-18 [oleic/stearic] and $\Delta 6 \mathrm{D}$ [DGLA/LA] activities. Nevertheless, $\omega-3$ intake from fish and linseed diets was effective in down regulating $\triangle 5 \mathrm{D}$-(ARA/DGLA) activity when compared with soybean diet. Results highlighted the ability of fish EPA and DHA intake in harnessing $\Delta 5 / 6 \mathrm{D}$ [EPA/ALA] and $\triangle 5 \mathrm{D}$ [DHA/DPA] activities in comparison with linseed and soybean groups. No differences were found between diets with different EPA:DHA ratios (Tab. 2).

\subsection{Determination of lipid mediators in plasma depending on the ingested amount of $A R A, E P A$ and DHA}

Plasma collected from dietary groups was analyzed to determine a wide range of lipid mediators from the family of prostaglandins, leukotrienes, thromboxanes, isoprostanes, resolvins, protectins, hydroxy and hydroperoxy acids. The correlation between the weekly dose of ARA, EPA and DHA given to rats and the further production of eicosanoids and docosanoids was also statistically analyzed.

Several hydroxy and hydroperoxy derivates, thromboxane and prostaglandin metabolites from ARA, EPA and DHA have been identified and levels are shown in Tab. 3. In detail, five EPA eicosanoids from the family of hydroxides (15HEPE and 12HEPE), hydroperoxides (15HpEPE and 12HpEPE), and a thromboxane $\left(\mathrm{TXB}_{3}\right)$ have been identified. From DHA, the 17HDoHE (hydroxide) and 17HpDoHE (hydroperoxide) were identified. Finally, a hydroxide and a prostaglandin derived from ARA, 11HETE and $\mathrm{PGE}_{2}$ respectively, have also been found in plasma samples from dietary interventions. After quantification and statistic comparison between groups, data revealed that dietary interventions with 1:1 and 2:1 EPA:DHA fish oils generally 
decreased levels of lipid mediators when compared with 1:2 fish oil, linseed and soybean groups.

The general comparison between dietary groups showed that levels of hydroxides and hydroperoxides from EPA and DHA were lower by 1:1 and 2:1 fish diets, while higher by 1:2 fish, linseed and soybean treatments. A similar trend was observed for ARA strong-inflammatory derivates. According to precursor PUFAs, they followed an opposite tendency in comparison with their derivates: ARA, EPA and DHA levels were higher in 1:1 and 2:1 animals. Particularly, $\mathrm{TXB}_{3}$ was only observed in linseed group and isoprostanes, leukotrienes, resolvins, and protectins were not detected. Interestingly, these results suggest that dietary $1: 1$ and $2: 1$ fish oil interventions were the best EPA:DHA proportions in order to reduce the production of lipid derived hydroxides and hydroperoxides and further strong pro-inflammatory substances.

In detail, levels of 15 and 12HEPEs (EPA hydroxides) significantly increased in linseed diets compared with soybean, 1:1, and 2:1 groups. Animals fed with 1:2 fish diet produced similar average levels as linseed group, but not statistically different when compared with other diets. In addition levels of 15 and 12HpEPE (EPA hydroperoxides) decreased in 1:1 and 2:1 fish oil supplementations compared with 1:2 and linseed groups, while soybean diet produced intermediate levels. A similar pattern was found for docosanoids derived from DHA: the level of $17 \mathrm{HpDoHE}$ was found to be higher in $1: 2$, soybean and linseed groups and lower in 1:1 fish diet; and the level of 17HDoHE significantly increased in linseed group compared with 1:1, 2:1 and soybean diets. Levels of 17HDoHE produced in 1:2 diet were similar to linseed one, but not statistically different when compared with other diets.

Moreover, the strong pro-inflammatory lipid mediators derived from ARA, 11HETE and $\mathrm{PGE}_{2}$, were significantly less-produced by dietary 1:1 and 2:1 interventions while linseed diet produced the highest concentrations for these compounds. Control soybean diet showed intermediate values but significantly higher than 1:1 fish oil treatment for 11HETE. Diet 1:2 produced similar values as linseed one, higher than other diets but not statistically different.

In addition, the analysis of the $\omega-3$ precursors, EPA and DHA, showed the highest levels by $1: 1$ and 2:1 fish diets when compared with 1:2, linseed and soybean groups. Accordingly, the level of $\omega-6$ ARA showed the same tendency as EPA and DHA, although only the comparison between $2: 1,1: 2$ and linseed groups was statistically different.

Finally, $\mathrm{TXB}_{3}$ was found in all animals $(n=7)$ fed with linseed supplement but it was barely identified in the rest of the groups $(n=1-3)$. Other searched compounds as 5HEPE, 8iso-PGF ${ }_{3 \alpha}$, 8iso- $\mathrm{PGF}_{2 \alpha}, \mathrm{PGD}_{3}, \mathrm{PGE}_{3}, 11 \mathrm{HDoHE}, 4 \mathrm{HDoHE}, \mathrm{RvD}_{1}, \mathrm{PD}_{\mathrm{x}}$, and $\mathrm{LTB}_{4}$ were not produced by any of the diets or were under the detection limits of the method.

Interestingly, the correlation analysis between the levels of lipid mediators in plasma and the dietary intakes of EPA and DHA, showed that the intake of 20C fatty acids (EPA and ARA) exerted a different effect over the production of metabolites when compared with 22C DHA. In detail, an increase in the ingested amount of EPA or ARA produced an enhancement in plasma levels of ARA, EPA and DHA (positive correlation 
indexes over 88-97\%), however it produced a decrease in hydroperoxide levels (primary oxidation products) with negative correlation indexes over $87-96 \%$, and a tendency was observed towards the decrease of secondary metabolites production (hydroxides, prostaglandins), but not statistically correlated. On the other hand, an increase in the ingested amount of DHA was weakly correlated with a higher level of ARA, EPA and DHA in plasma and a lower level of hydroperoxides. Moreover, DHA intake produced an inversion in the tendency of secondary metabolites production compared with EPA and ARA intakes towards an enhancement. Calculated Pearson indexes are shown in Tab. 4. Therefore, results suggested a decrease of the oxidation of ARA, EPA, and DHA and thus, a minor production of their metabolites when the dietary intake of EPA is higher; meanwhile, the increase of DHA in the diet reduced this antioxidant effect and even enhanced the production of secondary oxidative metabolites. Interestingly, these findings are in agreement with the stronger antioxidant effect exerted by 1:1 EPA:DHA and 2:1 EPA:DHA diets when compared with 1:2 EPA:DHA as it was previously described [20].

\section{Discussion}

Data of this study bring evidence that the consumption of EPA/DHA provokes a more anti-inflammatory than pro-inflammtory effect in animals fed with standard diets. In particular, fish oil supplements with 1:1 and 2:1 EPA:DHA proportions demonstrated to be the most effective treatments to produce an anti-inflammatory response compared with 1:2 EPA:DHA, linseed and soybean supplements. Such affirmation is based on the identification and quantitation of several lipid local mediators. In detail, ARA $\omega-6$ eicosanoids like $\mathrm{PGE}_{2}$ and $11 \mathrm{HETE}$, have been widely studied and identified as a key pro-inflammatory signaling molecules related with pro-aggregating, vasoconstrictive and immunosuppressive processes [9]; and they have also been associated with promotion of different human cancers including colon, lung, breast, head or neck [3]. On the other hand, derived eicosanoid and docosanoids from EPA and DHA have been related with protective effects on inflammation diseases [16], the regulation of tumor factors [18], or the reduction of CVD risk [10]. However, hydroxides and hydroperoxides derived from EPA and DHA were also considered as biomarkers of oxidative stress and weaker inflammatory substances than the corresponding ARA derivates [2,31]. In the same way, $\mathrm{TXB}_{3}$ derived from EPA is related with the inflammatory response, and a weaker pro-inflammatory product than corresponding series-2 thromboxanes from ARA [17].

One of the mechanisms by which EPA and DHA are thought to act is through substrate competition with ARA for enzymes that generate several inflammatory mediators $[2,10]$. As a consequence, when increasing amounts of $\omega-3$ substrate are included in the diet, LOXs and COXs would preferably regulate the production of $\omega-3$ derivates instead of $\omega-6$ ones. Therefore, strong-inflammation targets derived from $\omega-6$ PUFAs would be less produced and replaced by less harmful $\omega-3$ eicosanoids. Accordingly, it was observed a significant reduction of related pro-inflammatory $\omega-6$ eicosanoids after $1: 1$ and 2:1 diets compared with other groups; although levels of searched $\omega-3$ were not equally enhanced. On the other hand, 1:2 diet showed similar results as soybean (source of $\omega-6$ LA), and linseed (source of $\omega-3$ ALA). Therefore, not only a substrate competition for LOX and COX but other mechanisms may be implicated in the minor anti-inflammatory response observed in 1:2, linseed and soybean fed animals. 
It is known that LOXs regulate the synthesis of hydroperoxides (HpEPEs and HpDoHEs), which are further reduced into hydroxides (HEPEs and HDoHEs) through GPX activity. In addition, COXs regulate the synthesis of strong pro-inflammatory $\omega-6$ eicosanoids like 11HETE and $\mathrm{PGE}_{2}$, and less harmful $\omega-3$ ones like $\mathrm{TXB}_{3}$ [6]. Soybean, linseed and 1:2 groups showed significant lower GPX activities and higher hydroperoxides levels than 1:1 and 2:1 ones. Therefore, the down-regulation of GPX in soybean, linseed and 1:2 groups may be correlated with a decrease of hydroperoxides detoxification and consequently, with the highest values found for 12HpEPE, 15HpEPE, and 17HpDoHE. Moreover, a decrease of LOX activity after 1:1 and 2:1 interventions could explain the lowest hydroxide levels found in these diets despite the higher GPX activity observed. A similar trend was observed for COX products: soybean, linseed and 1:2 groups showed higher values than 1:1 and 2:1 ones. Specifically, $\mathrm{TXB}_{3}$ was preferably found after linseed treatments; and thus, it seemed that this diet had a direct influence on the pathway of this eicosanoid. In concordance with these findings, the statistical correlation analysis between weekly dose of EPA and DHA in the diet and the production of lipid metabolites showed that the increase of DHA amount in the diet lead to higher eicosanoid and docosanoids production. Meanwhile, the increase of EPA amount in the diet lead to lower metabolites production as it was observed when 1:2 EPA:DHA supplement was compared with 2:1 one. Therefore, in addition to the substrate competition for LOXs and COXs, it seemed that specific PUFAs profile of the diet may modulate enzymes activity towards different eicosanoid and docosanoids production.

In addition, not only enzymatic pathways but free radical oxidation mechanisms initiated by ROS also lead to the formation of described eicosanoid and docosanoids [32]. Accordingly, the susceptibility of fatty acids to oxidation is thought to be directly dependent on their degree of unsaturation, and subsequently, supplementations with highly unsaturated $\omega-3$ PUFA have been reported to increase oxidative damage [30]. Therefore, the higher unsaturation level of DHA may increase the susceptibility of the molecule to be oxidized compared to EPA, rending to a higher level of free radicals. Then, the supplement with higher DHA proportion (1:2) would produce a higher concentration of ROS and be more prone to suffer free radical oxidation processes than supplements with higher EPA or balanced ratios.

Richard et al. investigated the free radical-scavenging potential of $\omega-3$ and $\omega-6$ supplements in cell cultures studies [33]. They observed that supplemented cells with $\omega$ 3 PUFAs produced lower amounts of ROS than cells fed with $\omega-6$ ARA and LA despite the lower unsaturation level of the molecules. It was shown that $\omega-6$ series were more susceptible to oxidize than $\omega-3$ ones. Therefore, it was suggested that the susceptibility to oxidation of PUFA molecules is not as straightforward as hypothesized. Not only the lower degree of unsaturation leads to higher antioxidant activity, but the chemical structure may play an important role in the different antioxidant aptitude. Regarding to our results, $\omega-3$ ALA from linseed and $\omega-6$ LA from soybean seemed to be easier oxidized than $\omega-3$ EPA and DHA in mixtures $1: 1$ and $2: 1$, but the same results were found when compared with 1:2 mixture. In addition, the higher oxidizability suggested for soybean, linseed and 1:2 supplements was in concurrence with the lower PUFA levels found in plasma. Accordingly, PUFAs would be oxidized into the corresponding eicosanoid and docosanoids due to free radical reactions and enzymes pathways. The opposite trend was achieved for 1:1 and 2:1 where PUFA levels were higher and lipid derivates lower than the other diets. Other studies have also described the activation of 
the antioxidant response after $\omega$-3 EPA and DHA supplementation: enhance of SOD [34], and CAT activities [35], and genes related to endogenous antioxidant system [36]; although the different aptitude of EPA vs DHA have not been described yet.

As a conclusion for eicosanoid and docosanoids profiles, 1:1 and 2:1 interventions were the most effective treatments to reduce the synthesis of inflammatory lipid mediators. Different mechanisms were thought to modulate the activity of crucial enzymes involved in the generation of these compounds. In detail, it was suggested a competition for the same enzymes between substrates, and the different oxidizability between PUFAs due to their chemical structure and unsaturation degree. As a result, enriched diets with ALA, LA or 1:2 EPA:DHA exhibited lower anti-oxidative and antiinflammatory properties than 1:1 and 2:1 EPA:DHA.

In addition to the lipidomic analysis, the influence of dietary supplements on metabolic parameters like FAD, and FFA in plasma and tissues was measured. Results were finally correlated with previous data about inflammation, biochemical measurements, and oxidative stress. Fatty acid desaturases are one of the main targets for the treatment of metabolic related disorders, and the rate-limiting step in the biosynthesis of different PUFAs [5]. According to their activities, diets enriched with $\omega-3$ PUFAs from fish and linseed provoked a down-regulation of FAD involved in the transformation of LA into ARA. Therefore, intervention on the diet with $\omega-3$ PUFAs seemed to reduce $\omega-6$ ARA levels, the main substrate of pro-inflammatory $\omega-6$ eicosanoids. Interestingly, the high intake of ALA due to linseed diet did not address an increase of FADs activity involved in the synthesis of EPA and DHA from ALA. This finding is in agreement with Fu et al. who demonstrated ALA to be more prone to $\beta$-oxidation or excretion rather than elongate to EPA and DHA [37]. Our results suggested that linseed supplements were not effective to potentiate EPA and DHA endogenous synthesis. Therefore, some benefits directly attributed to fish PUFAs like production of specific anti-inflammatory metabolites could not be obtained by vegetal $\omega-3$ supplements.

A huge number of lipid species in plasma are triacylglycerol, glycerophospholipids and cholesterol esters. Increasing levels of these substances have been associated with chronic inflammation and CVD conditions [38]. In addition, a small fraction of total lipids, the FFA released from adipose tissue; are thought to exert relevant functions as signaling molecules participating in inflammation processes and oxidative stress [39]. Results showed that $\omega-6$ PUFA levels in plasma remained unaltered with the different dietary interventions; however, $\omega-3$ EPA and DHA increased after fish oil diets and $\omega-3$ ALA after linseed one as expected. The capacity of fish oil interventions to enrich the plasma FFA in DHA and EPA, and the anti-inflammatory effect attributed was already investigated [40]. As a consequence, animals fed with fish and linseed oils exhibited significantly lower $\omega-6 / \omega-3$ plasma ratios than the soybean group. It has been reported that the higher $\omega-6 / \omega-3$ ratio the greater pro-inflammatory conditions $[4,17]$. Furthermore, fish supplements were also effective to increase EPA and DHA incorporation into erythrocyte membranes, meanwhile ARA incorporation was reduced. Results were in agreement with those obtained by Massaro et al. [10]. Therefore, $\omega-6 / \omega-$ 3 ratios in tissues were also reduced due to fish oil diets. Nevertheless, although linseed fed animals showed similar $\omega-6 / \omega-3$ plasma ratios than fish groups, linseed diet was not effective to incorporate ALA into tissues. And thus, membrane $\omega-6 / \omega-3$ ratios showed lower values than obtained after fish oils. 
The decrease of the inflammation index $\omega-6 / \omega-3$ due to $\omega-3$ supplements was in concordance with the tendency to decrease CRP marker under fish and linseed diets observed in previous studies in the same animals [29]. Lower values of CRP indicate a reduction in general inflammation conditions linked to CVD [41]. Although CRP is regarded a potential inflammatory index, additional biomarkers like IL-6, IL-1 or TNF $\alpha$ would be desirable to strongly conclude the differences in the inflammatory status of dietary groups [42]. In any case, the general anti-inflammatory effect described by lipidomic and CRP data after $\omega-3$ fish diets may be also correlated with the general decrease observed in other parameters like TFA, TG, TC, LDL, and HbAlc when compared with soybean group [29]. Results for EPA:DHA interventions are in agreement with other studies that have suggested a protective role of fish PUFAs, essentially by improving the lipid profile and cardiovascular indexes [43], and with Reinders et al. who reported CRP levels to be inversely correlated to circulating $\omega-3$ PUFA concentrations [44]. To finish, the ability of fish diets to ameliorate general inflammatory conditions, specially 1:1 and 2:1 EPA:DHA, was in agreement with the effectiveness to reduce ROS concentration (higher ORAC), enhance the antioxidant endogenous system (SOD, and CAT), and reduce the oxidative damage in proteins $[20,29]$. The general decrease of oxidative stress and inflammatory markers may be correlated with the lower production of eicosanoid and docosanoids after 1:1 and 2:1 supplements as it was discussed above.

\section{Conclusion}

The investigation shed light on how PUFA composition of the diet may influence the synthesis of eicosanoid and docosanoids, and evidenced that 1:1 and 2:1 EPA:DHA supplements were the most effective treatments to reduce inflammation and oxidative stress when compared with 1:2 EPA:DHA, linseed and soybean ones. It was suggested a higher anti-oxidant and anti-inflammatory capacity of EPA vs DHA, and fish $\omega-3$ vs vegetal $\omega-3$ and $\omega-6$ PUFAs. It was also studied the influence of $\omega-6$ and $\omega-3$ supplements in FADs and thus, in the composition and $\omega-6 / \omega-3$ ratios in plasma and tissues. Results suggested greater anti-inflammatory conditions generated after $\omega-3$ interventions. These findings were in agreement with previous results that had shown the effect of 1:1 and 2:1 diets ameliorating inflammation and activating the antioxidant response of the organism. Therefore, this research evidenced that in addition to an adequate dietary proportion between $\omega-6$ and $\omega-3$ PUFA, the proportion between marine $\omega-3$ type lipids is also important and its intake could contribute towards the prevention of chronic inflammation and oxidative stress processes that have been correlated with metabolic syndrome, CVD, obesity, diabetes or even cancer [2,3]. Previous studies also supported the evidence of the protective effect of EPA and DHA intakes [16,31].

\section{Acknowledgements}

This work was supported by the Spanish Ministerio de Economía y Competitividad (AGL2013-49079-C2-1-R). The Consejo Superior de Investigaciones Científicas (CSIC) and the University of Santiago de Compostela are gratefully acknowledged for the doctoral fellowship to G.D. Xunta de Galicia and European Social Fund are also thankfully recognized by the financial support of the postdoctoral "Isidro Parga Pondal" contract to M.P and "Jae-Doc" contract to E.G-E.

\section{Table captions:}


Tab. 1: Plasma composition of FFA and FA of erythrocyte membranes (EM) from Wistar rats supplemented with different fish oils diets (EPA:DHA 1:1, 2:1 and 1:2), linseed oil or soybean oil. Results are expressed as percentage of total fatty acids $(\mathrm{mg} / 100 \mathrm{mg})$. Values are shown as means \pm SD. Values with different superscript letters in the same row indicate significant difference at $\mathrm{p}<0.05$ between dietary groups. 16:0 (palmitic acid), 16:1 107 (palmitoleic acid, PA), 18:0 (stearic acid), 18:1 $\omega 9$ (oleic acid, OA), 18:1 $\omega 7$ (vaccenic acid), 18:2 $\omega 6$ (LA), 18:3 $\omega 3$ (ALA), 20:3 $\omega 6$ (DGLA), 20:4 $\omega 6$ (ARA), 20:5 $\omega 3$ (EPA), 22:5 $\omega 3$ (DPA), 22:6 $\omega 3$ (DHA)

Tab. 2: Biochemical measurements (TFA, TG, TC, LDL, HDL, CRP, HbA1c), Antioxidant indexes (SOD, GPX and CAT activities, and ORAC), and FAD activity measurements obtained from the supplemented groups with different fish oils diets (EPA:DHA 1:1, 2:1 and 1:2), linseed oil or soybean oil. Values are shown as means \pm SD. Values with different superscript letters in the same row indicate significant difference at $\mathrm{p}<0.05$ between dietary groups.

Tab. 3: Levels of lipid mediators in plasma derived from ARA, EPA and DHA obtained from the dietary interventions. Results are expressed as as $\mathrm{ng} / \mathrm{mL}$ for derived eicosanoids and docosanoids, and $\mu \mathrm{g} / \mathrm{mL}$ for PUFAs. Values are shown as means $\pm \mathrm{SD}$. For the ANOVA analysis, data from 1:2 diet have not been considered for most of compounds due to the high variability observed. Values with different superscript letters in the same row indicate significant difference at $\mathrm{p}<0.05$ between dietary groups.

Tab. 4: Correlation Pearson indexes between lipid mediator levels in plasma and the weekly dietary dose of ARA, EPA and DHA.

\section{Figure captions:}

Fig.1: Cascade of formation to ARA, EPA and DHA oxidized derived compounds from enzymatic and non enzymatic pathways $[8,45]$.

\section{Supplementary electronic material captions:}

S1: Fatty acid composition of soybean oil, linseed oil and fish oil mixtures (EPA:DHA 1:1, 2:1 and 1:2) supplemented to Wistar rats. Results are expressed as a percentage of total fatty acids (mg/100mg of Total FA). Weekly dose of EPA, DHA, ALA, ARA and LA expressed as $\mathrm{mg} / \mathrm{kg}$ rat. Values are shown as means \pm SD. 16:0 (palmitic acid), 16:1 $\omega 7$ (palmitoleic acid, PA), 18:0 (stearic acid), 18:1 $\omega 9$ (oleic acid, OA), 18:1 $\omega 7$ (vaccenic acid), 18:2 $\omega 6$ (LA), 18:3 $\omega 3$ (ALA), 20:3 $\omega 6$ (DGLA), 20:4 $\omega 6$ (ARA), 20:5 $\omega 3$ (EPA), 22:5 $\omega 3$ (DPA), 22:6 13 (DHA)

S2: Retention times, collision energies and MS/MS transitions for ESI-LC-LIT/MS/MS

S3: Comparison of the plasma FFA profile from Wistar rats supplemented with different fish oils diets (EPA:DHA 1:1, 2:1 and 1:2), linseed oil or soybean oil. Results are expressed as percentage of total fatty acids (mg/100mg)

S4: Comparison of the FA erythrocyte membrane profile from Wistar rats supplemented with different fish oils diets (EPA:DHA 1:1, 2:1 and 1:2), linseed oil or soybean oil. Results are expressed as percentage of total fatty acids (mg/100mg) 
Table 1

\begin{tabular}{|c|c|c|c|c|c|c|c|c|c|c|c|c|c|c|c|c|c|c|c|c|}
\hline \multirow[b]{3}{*}{$F A$} & \multicolumn{4}{|c|}{$\begin{array}{l}\text { RATIO 1:1 } \\
\text { (EPA:DHA) }\end{array}$} & \multicolumn{4}{|c|}{$\begin{array}{l}\text { RATIO 2:1 } \\
\text { (EPA:DHA) }\end{array}$} & \multicolumn{4}{|c|}{$\begin{array}{l}\text { RATIO 1:2 } \\
\text { (EPA:DHA) }\end{array}$} & \multicolumn{4}{|c|}{ Soybean } & \multicolumn{4}{|c|}{ Linseed } \\
\hline & \multicolumn{2}{|c|}{$\begin{array}{c}\text { FFA } \\
\text { (Plasma) }\end{array}$} & \multicolumn{2}{|c|}{$\begin{array}{c}\text { FA } \\
\text { (EM) }\end{array}$} & \multicolumn{2}{|c|}{$\begin{array}{c}\text { FFA } \\
\text { (Plasma) }\end{array}$} & \multicolumn{2}{|c|}{$\begin{array}{c}\text { FA } \\
\text { (EM) }\end{array}$} & \multicolumn{2}{|c|}{$\begin{array}{c}\text { FFA } \\
\text { (Plasma) }\end{array}$} & \multicolumn{2}{|c|}{$\begin{array}{c}\text { FA } \\
\text { (EM) }\end{array}$} & \multicolumn{2}{|c|}{$\begin{array}{c}\text { FFA } \\
\text { (Plasma) }\end{array}$} & \multicolumn{2}{|c|}{$\begin{array}{c}\text { FA } \\
\text { (EM) }\end{array}$} & \multicolumn{2}{|c|}{$\begin{array}{c}\text { FFA } \\
\text { (Plasma) }\end{array}$} & \multicolumn{2}{|c|}{$\begin{array}{c}\text { FA } \\
\text { (EM) }\end{array}$} \\
\hline & $M E A N$ & $S D$ & $M E A N$ & $S D$ & $M E A N$ & $S D$ & $M E A N$ & $S D$ & $M E A N$ & $S D$ & $M E A N$ & $S D$ & $M E A N$ & $S D$ & $M E A N$ & $S D$ & $M E A N$ & $S D$ & $M E A N$ & $S D$ \\
\hline 16:0 (palmitic) & $32.72^{\mathrm{a}}$ & 1.1 & $22.61^{\mathrm{a}}$ & 1.5 & $31.69^{\mathrm{a}}$ & 1.4 & $22.55^{\mathrm{a}}$ & 0.6 & $31.63^{\mathrm{a}}$ & 1.1 & $22.58^{\mathrm{a}}$ & 0.7 & $32.12^{\mathrm{a}}$ & 0.8 & $22.48^{\mathrm{a}}$ & 0.8 & $31.03^{\mathrm{a}}$ & 1.1 & $23.76^{\mathrm{a}}$ & 2 \\
\hline $16: 1 \omega 7(\mathrm{PA})$ & $5.27^{\mathrm{ab}}$ & 0.8 & $0.53^{\mathrm{a}}$ & 0.1 & $5.43^{\mathrm{ab}}$ & 0.6 & $0.50^{\mathrm{a}}$ & 0.04 & $5.26^{\mathrm{ab}}$ & 0.6 & $0.60^{\mathrm{a}}$ & 0.1 & $6.09^{\mathrm{a}}$ & 0.5 & $0.63^{\mathrm{a}}$ & 0.1 & $4.86^{\mathrm{b}}$ & 0.6 & $0.56^{\mathrm{a}}$ & 0.1 \\
\hline 18:0 (stearic) & $10.71^{\mathrm{a}}$ & 2.5 & $14.09^{\mathrm{a}}$ & 1.5 & $9.51^{\mathrm{a}}$ & 3.5 & $15.09^{\mathrm{a}}$ & 0.8 & $8.86^{\mathrm{a}}$ & 1.2 & $15.22^{\mathrm{a}}$ & 0.7 & $9.12^{\mathrm{a}}$ & 0.6 & $14.60^{\mathrm{a}}$ & 0.3 & $8.73^{\mathrm{a}}$ & 1.2 & $12.83^{\mathrm{a}}$ & 2.2 \\
\hline $18: 1 \omega 9(\mathrm{OA})$ & $21.54^{\mathrm{a}}$ & 0.9 & $6.55^{\mathrm{a}}$ & 0.6 & $21.37^{\mathrm{a}}$ & 1.5 & $6.12^{\mathrm{a}}$ & 0.2 & $22.89^{\mathrm{a}}$ & 1.2 & $6.80^{\mathrm{a}}$ & 0.8 & $22.89^{\mathrm{a}}$ & 1.4 & $6.62^{\mathrm{a}}$ & 0.4 & $23.84^{\mathrm{a}}$ & 1.3 & $6.82^{\mathrm{a}}$ & 0.5 \\
\hline 18:1 $\omega 7$ (vaccenic) & $2.45^{\mathrm{a}}$ & 0.2 & $2.28^{\mathrm{a}}$ & 0.1 & $2.37^{\mathrm{a}}$ & 0.3 & $2.22^{\mathrm{a}}$ & 0.2 & $2.76^{\mathrm{a}}$ & 0.3 & $2.23^{\mathrm{a}}$ & 0.1 & $2.78^{\mathrm{a}}$ & 0.1 & $2.51^{\mathrm{a}}$ & 0.1 & $2.56^{\mathrm{a}}$ & 0.2 & $2.32^{\mathrm{a}}$ & 0.1 \\
\hline $18: 2 \omega 6(\mathrm{LA})$ & $17.31^{\mathrm{a}}$ & 1.9 & $7.63^{\mathrm{a}}$ & 0.7 & $17.50^{\mathrm{a}}$ & 2.2 & $7.64^{\mathrm{a}}$ & 0.3 & $17.72^{\mathrm{a}}$ & 1.7 & $7.44^{\mathrm{a}}$ & 0.7 & $17.31^{\mathrm{a}}$ & 1 & $6.95^{\mathrm{a}}$ & 0.3 & $18.11^{\mathrm{a}}$ & 1.3 & $7.45^{\mathrm{a}}$ & 0.6 \\
\hline $18: 3 \omega 3$ (ALA) & $0.94^{\mathrm{a}}$ & 0.4 & n.d. & n.d. & $1.01^{\mathrm{a}}$ & 0.1 & n.d. & n.d. & $0.84^{\mathrm{a}}$ & 0.4 & n.d. & n.d. & $0.96^{\mathrm{a}}$ & 0.04 & n.d & n.d & $1.73^{\mathrm{a}}$ & 0.3 & n.d & n.d \\
\hline $20: 3 \omega 6$ (DGLA) & n.d. & n.d. & $0.51^{\mathrm{a}}$ & 0.03 & n.d. & n.d. & $0.53^{\mathrm{a}}$ & 0.04 & n.d. & n.d. & $0.53^{\mathrm{a}}$ & 0.1 & n.d & n.d & $0.47^{\mathrm{a}}$ & 0.01 & n.d & n.d & $0.51^{\mathrm{a}}$ & 0.04 \\
\hline $20: 4 \omega 6$ (ARA) & $4.10^{\mathrm{a}}$ & 0.1 & $21.51^{\mathrm{ab}}$ & 1.3 & $4.55^{\mathrm{a}}$ & 0.7 & $21.63^{\mathrm{ab}}$ & 1.3 & $4.29^{\mathrm{a}}$ & 1.1 & $21.42^{\mathrm{a}}$ & 0.8 & $4.61^{\mathrm{a}}$ & 0.7 & $23.32^{\mathrm{b}}$ & 0.9 & $4.50^{\mathrm{a}}$ & 1 & $22.72^{\mathrm{ab}}$ & 1 \\
\hline $20: 5 \omega 3$ (EPA) & $0.49^{\mathrm{a}}$ & 0.1 & $1.03^{\mathrm{a}}$ & 0.2 & $0.66^{\mathrm{a}}$ & 0.2 & $1.09^{\mathrm{a}}$ & 0.2 & $0.44^{\mathrm{a}}$ & 0.1 & $0.89^{\mathrm{a}}$ & 0.1 & $0.20^{\mathrm{b}}$ & 0.02 & $0.56^{\mathrm{b}}$ & 0.1 & $0.36^{\mathrm{a}}$ & 0.1 & $0.82^{\mathrm{a}}$ & 0.1 \\
\hline $22: 5 \omega 3$ (DPA) & $0.67^{\mathrm{a}}$ & 0.2 & $2.77^{\mathrm{a}}$ & 0.2 & $0.83^{\mathrm{a}}$ & 0.3 & $3.02^{\mathrm{a}}$ & 0.2 & $0.76^{\mathrm{a}}$ & 0.2 & $2.53^{\mathrm{a}}$ & 0.1 & $0.31^{\mathrm{a}}$ & 0.2 & $2.09^{\mathrm{a}}$ & 0.1 & $0.76^{\mathrm{a}}$ & 0.2 & $2.73^{\mathrm{a}}$ & 0.2 \\
\hline 22:6 $\omega 3$ (DHA) & $2.06^{\mathrm{a}}$ & 0.3 & $7.11^{\mathrm{a}}$ & 0.8 & $2.83^{\mathrm{a}}$ & 0.7 & $6.82^{\mathrm{a}}$ & 0.5 & $2.54^{\mathrm{a}}$ & 0.4 & $6.92^{\mathrm{a}}$ & 0.4 & $1.36^{\mathrm{b}}$ & 0.2 & $5.70^{\mathrm{b}}$ & 0.2 & $1.84^{\mathrm{ab}}$ & 0.3 & $5.84^{\mathrm{b}}$ & 0.5 \\
\hline$\sum \omega 3$ & $4.16^{\mathrm{a}}$ & 0.3 & $10.91^{\mathrm{a}}$ & 0.4 & $5.33^{\mathrm{b}}$ & 0.3 & $10.94^{\mathrm{a}}$ & 0.3 & $4.58^{\mathrm{a}}$ & 0.3 & $10.34^{\mathrm{a}}$ & 0.2 & $2.83^{c}$ & 0.1 & $8.35^{\mathrm{b}}$ & 0.1 & $4.69^{a}$ & 0.2 & $9.39^{c}$ & 0.3 \\
\hline$\sum \omega 6$ & $21.41^{\mathrm{a}}$ & 1 & $29.64^{\mathrm{ab}}$ & 0.7 & $22.05^{\mathrm{a}}$ & 1.4 & $29.79^{\mathrm{ab}}$ & 0.5 & $22.01^{\mathrm{a}}$ & 1.4 & $29.39^{\mathrm{a}}$ & 0.5 & $21.92^{\mathrm{a}}$ & 0.9 & $30.74^{\mathrm{b}}$ & 0.4 & $22.61^{\mathrm{a}}$ & 1.2 & $30.68^{\mathrm{b}}$ & 0.5 \\
\hline$\sum$ SFA & $43.43^{\mathrm{a}}$ & 1.8 & $36.69^{\mathrm{a}}$ & 1.5 & $41.20^{\mathrm{a}}$ & 2.5 & $37.64^{\mathrm{a}}$ & 0.7 & $40.49^{\mathrm{a}}$ & 1.2 & $37.80^{\mathrm{a}}$ & 0.7 & $41.24^{\mathrm{a}}$ & 0.7 & $37.08^{\mathrm{a}}$ & 0.5 & $39.76^{\mathrm{a}}$ & 1.1 & $36.60^{\mathrm{a}}$ & 2.1 \\
\hline$\sum$ MUFA & $29.26^{\mathrm{a}}$ & 0.7 & $9.37^{\mathrm{a}}$ & 0.3 & $29.17^{\mathrm{a}}$ & 0.8 & $8.84^{b}$ & 0.1 & $30.91^{\mathrm{b}}$ & 0.7 & $9.63^{\mathrm{a}}$ & 0.3 & $31.76^{\mathrm{b}}$ & 0.7 & $9.76^{\mathrm{a}}$ & 0.2 & $31.26^{\mathrm{b}}$ & 0.7 & $9.70^{\mathrm{a}}$ & 0.2 \\
\hline$\sum$ PUFA & $25.57^{\mathrm{a}}$ & 0.5 & $40.56^{\mathrm{ab}}$ & 0.5 & $27.38^{\mathrm{b}}$ & 0.7 & $40.73^{b}$ & 0.4 & $26.59^{\mathrm{ab}}$ & 0.7 & $39.73^{\mathrm{a}}$ & 0.4 & $24.75^{\mathrm{a}}$ & 0.4 & $39.09^{\mathrm{a}}$ & 0.3 & $27.30^{\mathrm{b}}$ & 0.5 & $40.07^{\mathrm{ab}}$ & 0.4 \\
\hline$\omega 6 / \omega 3$ & 5.15 & & 2.72 & & 4.1 & & 2.72 & & 4.81 & & 2.84 & & 7.7 & & 3.68 & & 4.82 & & 3.27 & \\
\hline
\end{tabular}


Table 2

\begin{tabular}{|c|c|c|c|c|c|c|c|c|c|c|}
\hline Group & \multicolumn{2}{|c|}{$\begin{array}{l}\text { RATIO 1:1 } \\
\text { (EPA:DHA) }\end{array}$} & \multicolumn{2}{|c|}{$\begin{array}{c}\text { RATIO 2:1 } \\
\text { (EPA:DHA) }\end{array}$} & \multicolumn{2}{|c|}{$\begin{array}{l}\text { RATIO 1:2 } \\
\text { (EPA:DHA) }\end{array}$} & \multicolumn{2}{|c|}{ Soybean } & \multicolumn{2}{|c|}{ Linseed } \\
\hline Biochemical measurements & MEAN & $S D$ & MEAN & $S D$ & MEAN & $S D$ & MEAN & $S D$ & $M E A N$ & $S D$ \\
\hline TFA (mg/dL) & $267.7^{\mathrm{ab}}$ & 38.4 & $233.8^{\mathrm{a}}$ & 24.2 & $280.8^{\mathrm{ab}}$ & 30.3 & $355.6^{\mathrm{c}}$ & 87.7 & $316.9^{\mathrm{abc}}$ & 61 \\
\hline $\mathrm{TG}(\mathrm{mg} / \mathrm{dL})$ & $93.8^{\mathrm{a}}$ & 67.8 & $64^{\mathrm{a}}$ & 23.4 & $83.1^{\mathrm{a}}$ & 10.4 & $108.5^{\mathrm{a}}$ & 51.9 & $73.5^{\mathrm{a}}$ & 25.2 \\
\hline $\mathrm{TC}(\mathrm{mg} / \mathrm{dL})$ & $102^{\mathrm{a}}$ & 26.5 & $98^{\mathrm{a}}$ & 14.8 & $112.3^{\mathrm{a}}$ & 20.8 & $125.8^{\mathrm{a}}$ & 16.5 & $133.4^{\mathrm{a}}$ & 41.2 \\
\hline LDL $(\mathrm{mg} / \mathrm{dL})$ & $8.6^{\mathrm{a}}$ & 3.3 & $7.4^{\mathrm{a}}$ & 0.8 & $8.3^{\mathrm{a}}$ & 1.3 & $10.4^{\mathrm{a}}$ & 2.2 & $10.1^{\mathrm{a}}$ & 7.1 \\
\hline $\mathrm{HDL}(\mathrm{mg} / \mathrm{dL})$ & $41.2^{\mathrm{a}}$ & 11.1 & $42.3^{\mathrm{a}}$ & 7.9 & $47.3^{\mathrm{a}}$ & 8.1 & $51.3^{\mathrm{a}}$ & 7.8 & $49.7^{\mathrm{a}}$ & 9.1 \\
\hline $\mathrm{HDL} / \mathrm{LDL}$ & \multicolumn{2}{|c|}{$4.8^{\mathrm{a}}$} & \multicolumn{2}{|c|}{$5.7^{\mathrm{b}}$} & \multicolumn{2}{|c|}{$5.7^{\mathrm{b}}$} & \multicolumn{2}{|c|}{$4.9^{\mathrm{a}}$} & \multicolumn{2}{|c|}{$4.9^{\mathrm{a}}$} \\
\hline CRP (ug/mL) & $147^{\mathrm{a}}$ & 20.5 & $147.1^{\mathrm{a}}$ & 22.4 & $140.1^{\mathrm{a}}$ & 52.7 & $172.9^{\mathrm{a}}$ & 38.2 & $142.9^{\mathrm{a}}$ & 52 \\
\hline HbAlc (\%) & $4.1^{\mathrm{a}}$ & 0.2 & $4.4^{\mathrm{a}}$ & 0.7 & $4.17^{\mathrm{a}}$ & 0.3 & $6.4^{\mathrm{b}}$ & 1 & $6.3^{\mathrm{b}}$ & 1.8 \\
\hline \multicolumn{11}{|l|}{ Antioxidant indexes } \\
\hline ORAC $(\mathrm{mg} / \mathrm{dL})$ & $48.2^{\mathrm{a}}$ & 16.9 & $23.6^{\mathrm{b}}$ & 6 & $26.4^{\mathrm{b}}$ & 9 & $30.3^{\mathrm{b}}$ & 9.6 & $24.7^{\mathrm{b}}$ & 9.7 \\
\hline $\mathrm{SOD}(\mathrm{U} / \mathrm{gHb})$ & $2129.2^{\mathrm{a}}$ & 586.5 & $1880.9^{\mathrm{ab}}$ & 341.2 & $1226.1^{\mathrm{b}}$ & 517.4 & $1443.8^{\mathrm{ab}}$ & 426.2 & 1230.6 & $283.9^{\mathrm{b}}$ \\
\hline GPX (U/gHb) & $107.1^{\mathrm{a}}$ & 15 & $116.7^{\mathrm{b}}$ & 30.7 & $67.7^{\mathrm{c}}$ & 34.5 & $101.5^{\mathrm{abc}}$ & 38.2 & $71.1^{\mathrm{c}}$ & 9.6 \\
\hline $\mathrm{CAT}(\mathrm{mmol} / \mathrm{min} / \mathrm{gHb})$ & $57.4^{\mathrm{a}}$ & 11.1 & $76.7^{\mathrm{a}}$ & 28.2 & $61.4^{\mathrm{a}}$ & 13.2 & $41.5^{\mathrm{a}}$ & 34.6 & $37.2^{\mathrm{a}}$ & 20.9 \\
\hline \multicolumn{11}{|l|}{ FAD activity } \\
\hline SCD-16 [palmitoleic/palmitic] & \multicolumn{2}{|c|}{0.1} & \multicolumn{2}{|c|}{0.1} & \multicolumn{2}{|c|}{0.1} & \multicolumn{2}{|c|}{0.1} & \multicolumn{2}{|c|}{0.1} \\
\hline SCD-18 [oleic/stearic] & \multicolumn{2}{|c|}{0.9} & \multicolumn{2}{|c|}{0.9} & \multicolumn{2}{|c|}{0.8} & \multicolumn{2}{|c|}{0.9} & \multicolumn{2}{|c|}{1} \\
\hline$\Delta 5 \mathrm{D}[\mathrm{ARA} / \mathrm{DGLA}]$ & \multicolumn{2}{|c|}{48.4} & \multicolumn{2}{|c|}{49} & \multicolumn{2}{|c|}{45.7} & \multicolumn{2}{|c|}{68.1} & \multicolumn{2}{|c|}{48.4} \\
\hline$\Delta 6 \mathrm{D}[\mathrm{DGLA} / \mathrm{LA}]$ & \multicolumn{2}{|c|}{0.03} & \multicolumn{2}{|c|}{0.03} & \multicolumn{2}{|c|}{0.04} & \multicolumn{2}{|c|}{0.03} & \multicolumn{2}{|c|}{0.04} \\
\hline$\Delta 5 / 6 \mathrm{D}[\mathrm{EPA} / \mathrm{ALA}]$ & \multicolumn{2}{|c|}{3.6} & 4.4 & & 4. & & 2. & & 2. & \\
\hline$\Delta 5 \mathrm{D}[\mathrm{DHA} / \mathrm{DPA}]$ & 8.2 & & 7.5 & & 8. & & 7.8 & & 6 . & \\
\hline
\end{tabular}


Table 3

\begin{tabular}{|c|c|c|c|c|c|c|c|c|c|c|}
\hline \multirow[t]{2}{*}{ Group } & \multicolumn{2}{|c|}{$\begin{array}{l}\text { RATIO 1:1 } \\
\text { (EPA:DHA) }\end{array}$} & \multicolumn{2}{|c|}{$\begin{array}{c}\text { RATIO 2:1 } \\
\text { (EPA:DHA) }\end{array}$} & \multicolumn{2}{|c|}{$\begin{array}{l}\text { RATIO 1:2 } \\
\text { (EPA:DHA) }\end{array}$} & \multicolumn{2}{|c|}{ Soybean } & \multicolumn{2}{|c|}{ Linseed } \\
\hline & $M E A N$ & $S D$ & $M E A N$ & $S D$ & $M E A N$ & $S D$ & $M E A N$ & $S D$ & $M E A N$ & $S D$ \\
\hline \multicolumn{11}{|c|}{ Eicosanoids from EPA $(\mathrm{ng} / \mathrm{mL})$} \\
\hline 12HEPE & $59^{\mathrm{a}}$ & 46 & $65^{\mathrm{a}}$ & 23 & 299 & 356 & $65^{\mathrm{a}}$ & 40 & $250^{\mathrm{b}}$ & 62 \\
\hline 15HEPE & $3.3^{\mathrm{a}}$ & 1.1 & $3.7^{\mathrm{a}}$ & 1.3 & 6.2 & 3.7 & $3.2^{\mathrm{a}}$ & 0.7 & $7.1^{\mathrm{b}}$ & 1.3 \\
\hline $12 \mathrm{HpEPE}$ & $387^{\mathrm{a}}$ & 300 & $411^{\mathrm{a}}$ & 279 & $1269^{b}$ & 524 & $640^{\mathrm{ab}}$ & 376 & $1462^{\mathrm{b}}$ & 1043 \\
\hline $15 \mathrm{HpEPE}$ & $388^{\mathrm{a}}$ & 128 & $403^{\mathrm{ab}}$ & 164 & 898 & 574 & $691^{\mathrm{bc}}$ & 280 & $968^{\mathrm{c}}$ & 156 \\
\hline $\mathrm{TXB}_{3}$ & $3.3^{\mathrm{a}}$ & 0.004 & n.d. & n.d. & 4.4 & 1.0 & $3.5^{\mathrm{a}}$ & 0.2 & $4.2^{\mathrm{b}}$ & 0.3 \\
\hline \multicolumn{11}{|c|}{ Docosanoids from DHA (ng/mL) } \\
\hline 17HDoHE & $40^{\mathrm{a}}$ & 20 & $41^{\mathrm{a}}$ & 11 & 173 & 175 & $64^{\mathrm{a}}$ & 56 & $134^{\mathrm{b}}$ & 23 \\
\hline 17HpDoHE & $1482^{\mathrm{a}}$ & 691 & $1596^{\mathrm{a}}$ & 700 & $1853^{\mathrm{a}}$ & 553 & $2175^{\mathrm{a}}$ & 475 & $2159^{\mathrm{a}}$ & 927 \\
\hline \multicolumn{11}{|c|}{ Eicosanoids from ARA $(\mathrm{ng} / \mathrm{ml})$} \\
\hline 11HETE & $3.9^{\mathrm{a}}$ & 2.1 & $4.4^{\mathrm{ab}}$ & 1.5 & 9.9 & 9.6 & $6.7^{\mathrm{b}}$ & 2.2 & $13.6^{\mathrm{c}}$ & 1.8 \\
\hline $\mathrm{PGE}_{2}$ & $8.2^{\mathrm{a}}$ & 1.8 & $9.9^{\mathrm{a}}$ & 1.4 & 40.1 & 42 & $18.7^{\mathrm{a}}$ & 12.4 & $38.8^{\mathrm{b}}$ & 8.7 \\
\hline \multicolumn{11}{|c|}{ PUFA precursors (ng/uL) } \\
\hline EPA & $2.6^{\mathrm{a}}$ & 1.4 & $2.5^{\mathrm{a}}$ & 0.6 & $1.4^{\mathrm{b}}$ & 0.8 & $1.1^{\mathrm{b}}$ & 0.3 & $1.1^{\mathrm{b}}$ & 0.3 \\
\hline DHA & $13.1^{\mathrm{a}}$ & 5.9 & $12.6^{\mathrm{ab}}$ & 3.9 & $9.2^{\mathrm{abc}}$ & 3.5 & $7.4^{\mathrm{bc}}$ & 2.8 & $6^{\mathrm{c}}$ & 1.7 \\
\hline ARA & $48^{\mathrm{ab}}$ & 8 & $51^{\mathrm{a}}$ & 9 & $36^{\mathrm{b}}$ & 12 & $43^{\mathrm{ab}}$ & 11 & $37^{\mathrm{b}}$ & 6 \\
\hline
\end{tabular}


Table 4

\begin{tabular}{|c|c|c|c|}
\hline \multirow[b]{2}{*}{ Compounds } & $\begin{array}{c}\text { Weekely intake } \\
\text { of EPA }\end{array}$ & $\begin{array}{c}\text { Weekely intake } \\
\text { of DHA }\end{array}$ & $\begin{array}{c}\text { Weekely intake } \\
\text { of ARA }\end{array}$ \\
\hline & \multicolumn{3}{|c|}{ Correlation Pearson indexes (-1 to 1) } \\
\hline 12HEPE & 0,1781 & 0,6898 & 0,1066 \\
\hline $15 \mathrm{HEPE}$ & 0,0486 & 0,7375 & $-0,0169$ \\
\hline 12HpEPE & $-0,9122$ & $-0,7924$ & $-0,9120$ \\
\hline $15 \mathrm{HpEPE}$ & $-0,9621$ & $-0,7272$ & $-0,9609$ \\
\hline TXB3 & 0,5295 & 0,2605 & 0,4746 \\
\hline 17HDoHE & $-0,1928$ & 0,4941 & $-0,2623$ \\
\hline 17HpDoHE & $-0,8662$ & $-0,6991$ & $-0,8820$ \\
\hline 11HETE & $-0,2209$ & 0,3144 & $-0,2934$ \\
\hline PGE2 & $-0,4604$ & 0,2172 & $-0,5247$ \\
\hline EPA & 0,9417 & 0,4363 & 0,9639 \\
\hline DHA & 0,9519 & 0,5521 & 0,9683 \\
\hline ARA & 0,8803 & 0,2146 & 0,9121 \\
\hline
\end{tabular}


Figure 1

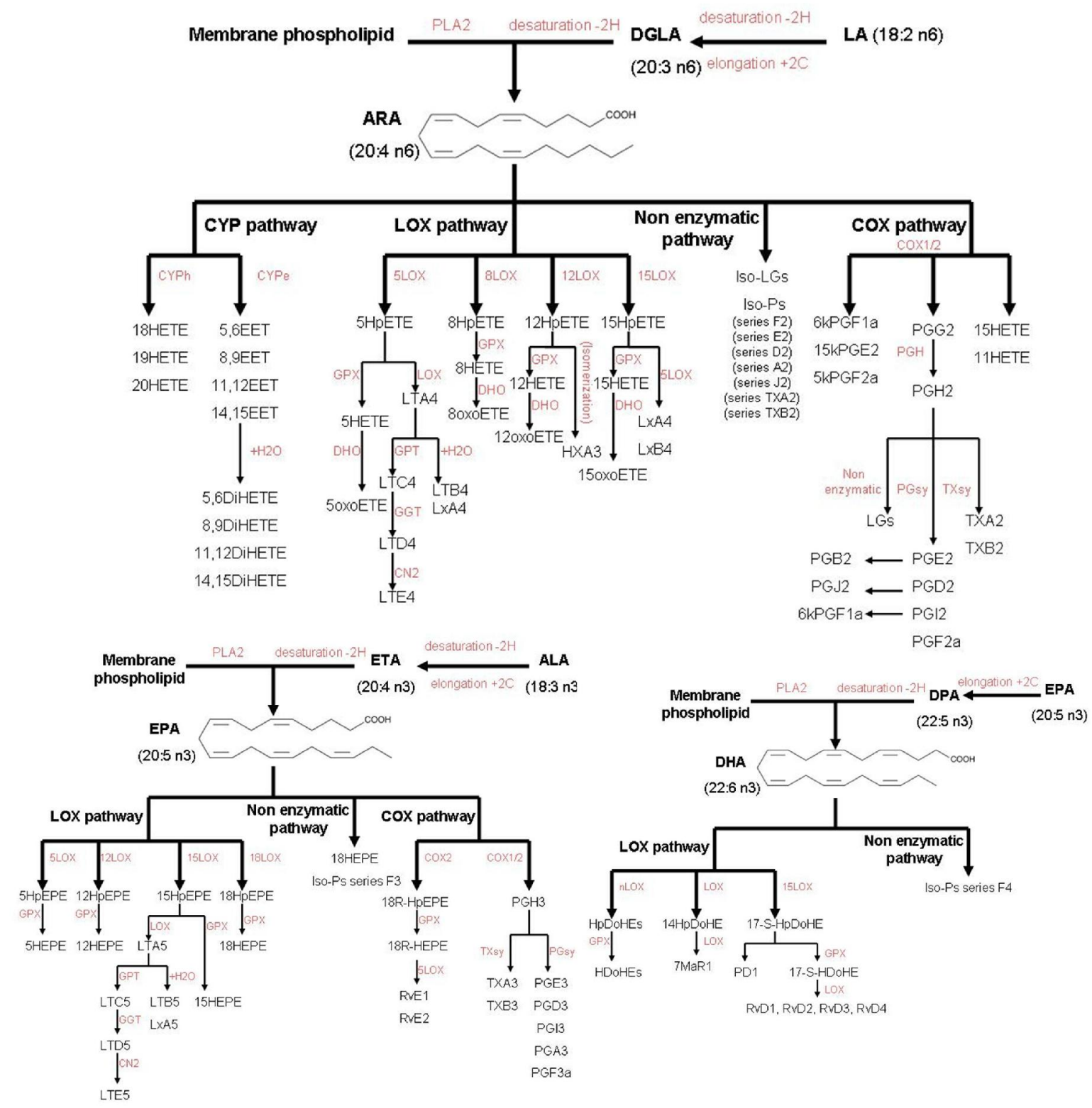


S1

\begin{tabular}{|c|c|c|c|c|c|c|c|c|c|c|}
\hline \multirow[b]{2}{*}{ FATTY ACID } & \multicolumn{2}{|c|}{$\begin{array}{l}\text { RATIO 1:1 } \\
\text { (EPA:DHA) }\end{array}$} & \multicolumn{2}{|c|}{$\begin{array}{l}\text { RATIO 2:1 } \\
\text { (EPA:DHA) }\end{array}$} & \multicolumn{2}{|c|}{$\begin{array}{c}\text { RATIO 1:2 } \\
\text { (EPA:DHA) }\end{array}$} & \multicolumn{2}{|c|}{ SOYBEAN } & \multicolumn{2}{|c|}{ LINSEED } \\
\hline & $M E A N$ & $S D$ & $M E A N$ & $S D$ & $M E A N$ & $S D$ & $M E A N$ & $S D$ & $M E A N$ & $S D$ \\
\hline 16:0 (palmitic) & 10.15 & 0.2 & 9.09 & 0.03 & 10.98 & 0.1 & 17.78 & 0.1 & 5.73 & 0.03 \\
\hline $16: 1 \omega 7(\mathrm{PA})$ & 4.99 & 0.04 & 4.57 & 0.02 & 5.39 & 0.03 & 0.90 & 0.03 & 0.11 & 0.01 \\
\hline 18:0 (stearic) & 2.94 & 0.03 & 2.95 & 0 & 2.97 & 0.01 & 2.07 & 0.01 & 4.75 & 0.02 \\
\hline $18: 1 \omega 9(\mathrm{OA})$ & 6.41 & 0.06 & 6.18 & 0 & 6.61 & 0.04 & 18.75 & 0.03 & 21.37 & 0.06 \\
\hline 18:1 $\omega 7$ (vaccenic) & 1.91 & 0.03 & 1.93 & 0.02 & 1.95 & 0.02 & 1.52 & 0.02 & 1.11 & 0.01 \\
\hline $18: 2 \omega 6$ (LA) & 0.65 & 0.01 & 0.61 & 0 & 0.65 & 0.02 & 47.55 & 0.01 & 16.76 & 0.03 \\
\hline $20: 0$ & 0.32 & 0.01 & 0.39 & 0.01 & 0.20 & 0 & 0.00 & 0 & 0.00 & 0 \\
\hline $18: 3 \omega 3$ (ALA) & 0.36 & 0.01 & 0.32 & 0 & 0.33 & 0.02 & 4.00 & 0.04 & 50.02 & 0.1 \\
\hline $20: 1 \omega 9$ & 0.98 & 0.03 & 1.39 & 0.01 & 0.63 & 0.02 & 1.43 & 0.09 & n.d. & n.d. \\
\hline $18: 4 \omega 3$ & 1.51 & 0.02 & 1.56 & 0.02 & 1.64 & 0 & 0.15 & 0 & n.d. & n.d. \\
\hline $20: 2 \omega 6$ & 0.21 & 0 & 0.28 & 0.01 & 0.17 & 0.01 & 0.20 & 0.05 & n.d. & n.d. \\
\hline $20: 3 \omega 6$ (DGLA) & 0.22 & 0.01 & 0.27 & 0.01 & 0.15 & 0 & 0.00 & 0 & n.d. & n.d. \\
\hline $20: 4 \omega 6$ (ARA) & 1.68 & 0.04 & 1.98 & 0.03 & 1.16 & 0.02 & 0.40 & 0.02 & n.d. & n.d. \\
\hline $22: 1 \omega 11$ & 1.14 & 0.01 & 1.58 & 0.02 & 0.45 & 0.01 & 1.08 & 0 & n.d. & n.d. \\
\hline $22: 1 \omega 9$ & 0.28 & 0.03 & 0.37 & 0.03 & 0.19 & 0.02 & 0.25 & 0.02 & n.d. & n.d. \\
\hline $20: 4 \omega 3$ & 1.02 & 0.02 & 1.31 & 0.02 & 0.75 & 0.01 & 0.20 & 0.03 & n.d. & n.d. \\
\hline $20: 5 \omega 3$ (EPA) & 25.09 & 0.1 & 32.43 & 0.06 & 17.33 & 0.03 & 0.70 & 0.02 & n.d. & n.d. \\
\hline $24: 1 \omega 9$ & 0.38 & 0 & 0.55 & 0.02 & 0.25 & 0.01 & 0.28 & 0.05 & n.d. & n.d. \\
\hline $22: 5 \omega 3$ (DPA) & 4.30 & 0.05 & 5.24 & 0.02 & 2.60 & 0.1 & 0.26 & 0.01 & n.d. & n.d. \\
\hline $22: 6 \omega 3$ (DHA) & 25.70 & 0.2 & 17.98 & 0.03 & 34.85 & 0.1 & 1.15 & 0.03 & n.d. & n.d. \\
\hline Total $\omega 3$ PUFA & 57.97 & 0.07 & 58.84 & 0.03 & 57.51 & 0.05 & 6.47 & 0.02 & 50.02 & 0.1 \\
\hline Total $\omega 6$ PUFA & 2.76 & 0.01 & 3.14 & 0.01 & 2.14 & 0.01 & 48.15 & 0.02 & 16.76 & 0.03 \\
\hline Total SFA & 18.52 & 0.2 & 17.05 & 0.02 & 19.68 & 0.1 & 21.17 & 0.1 & 10.63 & 0.06 \\
\hline Total MUFA & 17.22 & 0.1 & 17.14 & 0.07 & 17.43 & 0.1 & 24.21 & 0.1 & 22.59 & 0.06 \\
\hline Total PUFA & 64.26 & 0.3 & 65.81 & 0.08 & 62.90 & 0.2 & 54.62 & 0.03 & 66.78 & 0.1 \\
\hline weekly dose of EPA & \multicolumn{2}{|c|}{159.30} & \multicolumn{2}{|c|}{205.84} & \multicolumn{2}{|c|}{110.03} & \multicolumn{2}{|c|}{4.45} & & \\
\hline weekly dose of DHA & \multicolumn{2}{|c|}{163.12} & \multicolumn{2}{|c|}{114.15} & \multicolumn{2}{|c|}{221.24} & \multicolumn{2}{|c|}{7.31} & & \\
\hline weekly dose of ARA & \multicolumn{2}{|c|}{10.65} & \multicolumn{2}{|c|}{12.55} & \multicolumn{2}{|c|}{7.37} & \multicolumn{2}{|c|}{2.54} & & \\
\hline weekly dose of ALA & \multicolumn{2}{|c|}{2.29} & \multicolumn{2}{|c|}{2.06} & \multicolumn{2}{|c|}{2.09} & \multicolumn{2}{|c|}{25.39} & \multicolumn{2}{|c|}{317.56} \\
\hline weekly dose of LA & \multicolumn{2}{|c|}{4.13} & \multicolumn{2}{|c|}{3.88} & \multicolumn{2}{|c|}{4.15} & \multicolumn{2}{|c|}{301.86} & \multicolumn{2}{|c|}{106.39} \\
\hline
\end{tabular}




\begin{tabular}{|c|c|c|c|}
\hline \multirow[t]{2}{*}{ Compound } & \multirow{2}{*}{$\begin{array}{c}\text { Retention Time } \\
\text { (min) }\end{array}$} & \multicolumn{2}{|c|}{ LIT parameters } \\
\hline & & Collision energy (eV) & Quantification transition $(\mathrm{m} / \mathrm{z})$ \\
\hline 8iso-PGF $_{3 \alpha}$ & 6.79 & 30 & $351>253$ \\
\hline $\mathrm{TXB}_{3}$ & 6.97 & 19 & $367>195$ \\
\hline $\mathrm{PGD}_{3} / \mathrm{PGE}_{3}$ & 7.67 & 19 & $349>313$ \\
\hline 8iso-PGF $2 \alpha$ & 8.28 & 28 & $353>299$ \\
\hline $\mathrm{PGE}_{2}$ & 9.09 & 20 & $351>315$ \\
\hline $\mathbf{R v D}_{1}$ & 9.80 & 25 & $375>141$ \\
\hline $\mathbf{P D}_{\mathbf{x}}$ & 12.89 & 30 & $359>153$ \\
\hline $\mathbf{L T B}_{4}$ & 13.79 & 27 & $335>195$ \\
\hline 15НрЕРE & 17.36 & 20 & $333>315$ \\
\hline 12НpЕРЕ & 17.80 & 25 & $333>315$ \\
\hline 15HEPE & 17.92 & 27 & $317>219$ \\
\hline 12HEPE & 18.72 & 27 & $317>179$ \\
\hline 5HEPE & 20.47 & 25 & $317>255$ \\
\hline 17HрDoHE & 21.90 & 26 & $359>341$ \\
\hline 17HDoHE & 21.94 & 27 & $343>245$ \\
\hline 11HETE & 22.09 & 30 & $319>167$ \\
\hline 12HETEd $_{8}$ & 22.66 & 30 & $325>307$ \\
\hline 11HDoHE & 23.20 & 27 & $343>149$ \\
\hline 4HDoHE & 23.64 & 27 & $343>281$ \\
\hline EPA & 24.43 & 27 & $301>257$ \\
\hline DHA & 24.93 & 30 & $327>283$ \\
\hline ARA & 25.10 & 30 & $303>259$ \\
\hline
\end{tabular}




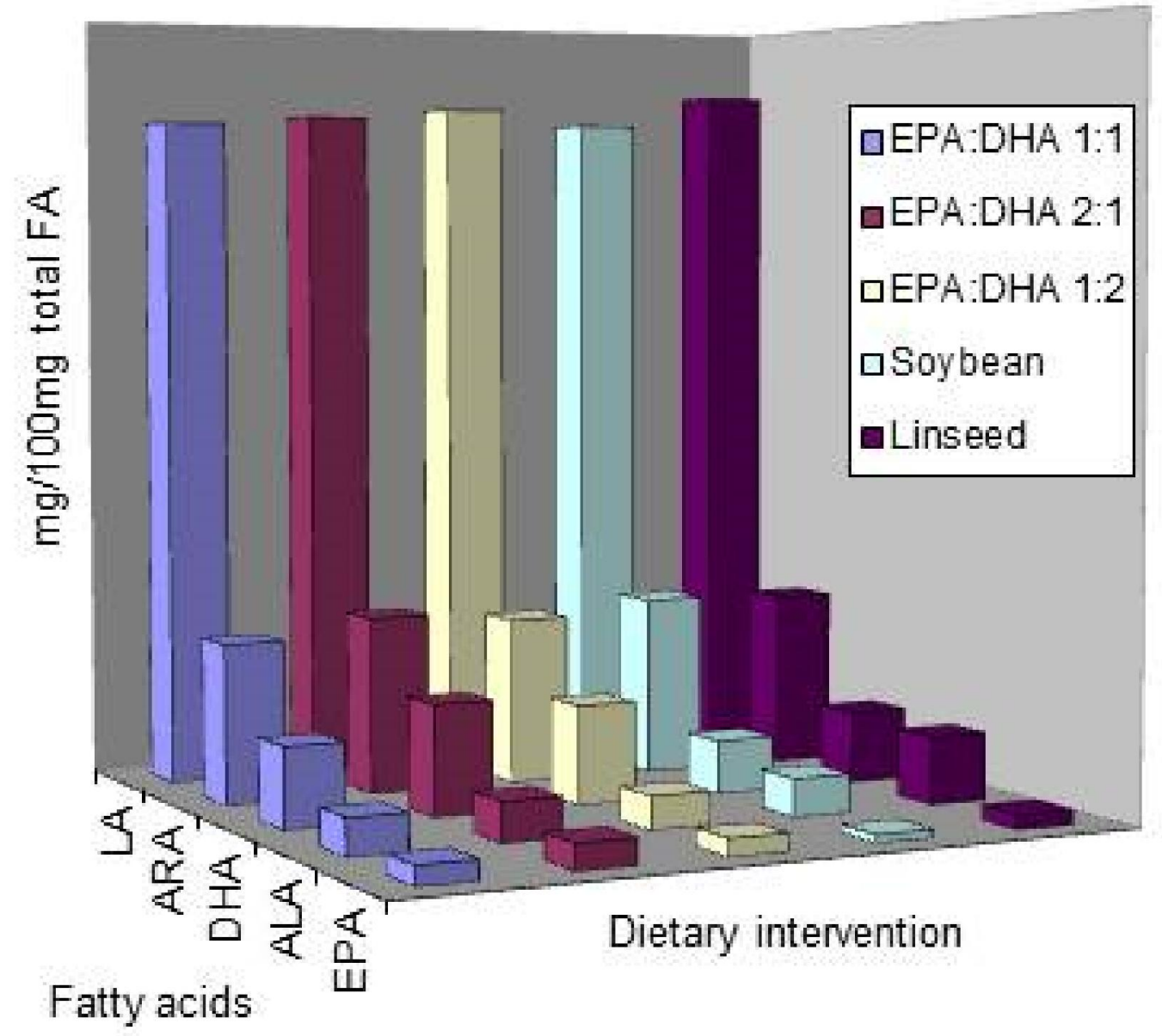




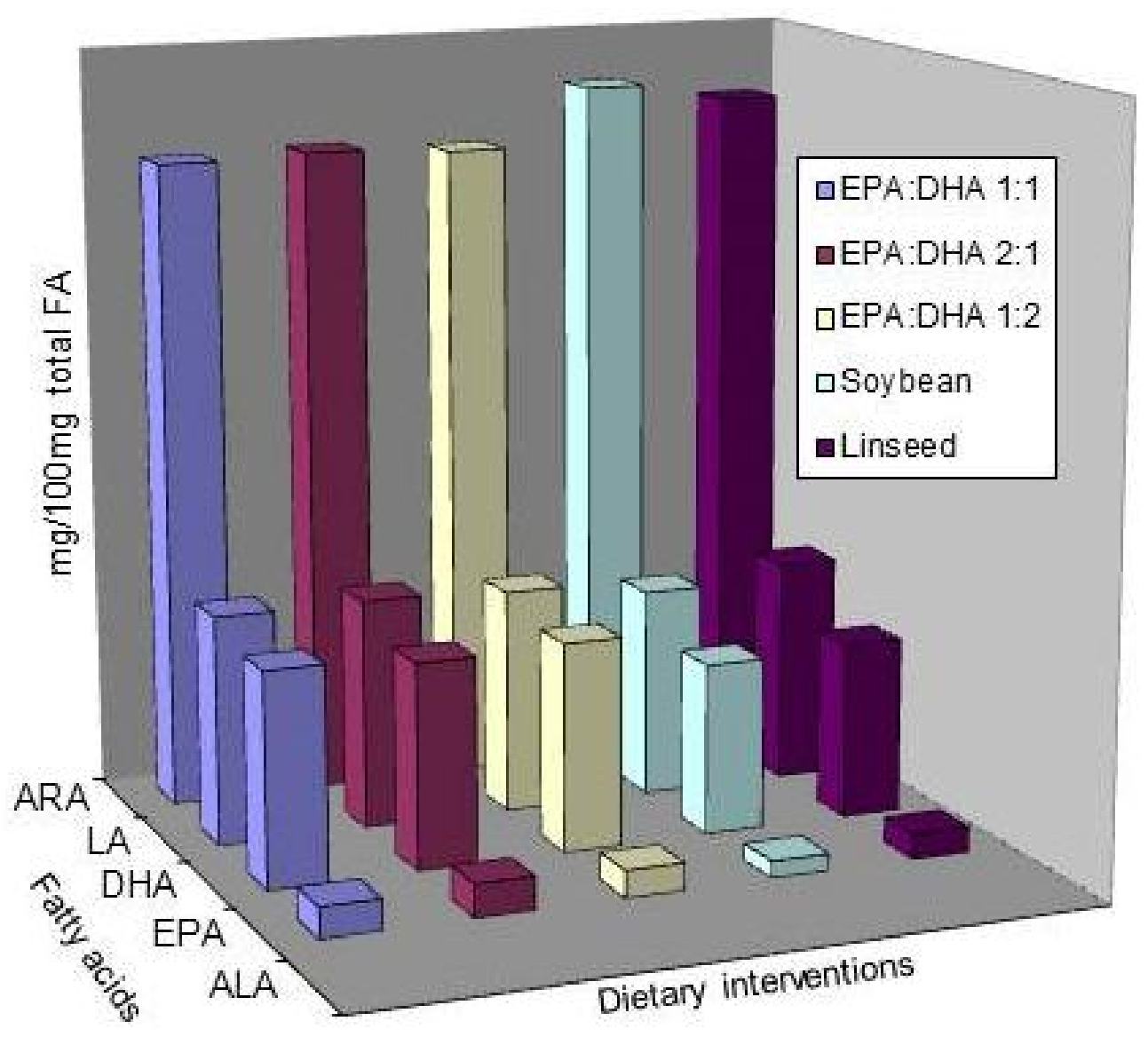




\section{References}

[1] Sun Y, Oh SF, Uddin J, Yang R, Gotlinger K, Campbell E, Colgan SP, Petasis NA, Serhan CN. Resolvin D1 and its aspirin-triggered 17R epimer - Stereochemical assignments, anti-inflammatory properties, and enzymatic inactivation. J Biol Chem. 2007;282:9323-9334.

[2] Sears B, Ricordi C. Role of fatty acids and polyphenols in inflammatory gene transcription and their impact on obesity, metabolic syndrome and diabetes. Eur Rev Med Pharmacol Sci. 2012;16:1137-1154.

[3] Greene ER, Huang S, Serhan CN, Panigrahy D. Regulation of inflammation in cancer by eicosanoids. Prostaglandins Other Lipid Mediat. 2011;96:27-36.

[4] Sears B. The Anti-inflammation Zone. New York: Regan Books; 2005.

[5] Vessby B, Gustafsson I, Tengblad S, Berglund L. Indices of fatty acid desaturase activity in healthy human subjects: effects of different types of dietary fat. Br J Nutr. 2013;110:871-879.

[6] Massey KA, Nicolaou A. Lipidomics of oxidized polyunsaturated fatty acids. Free Radical Biology and Medicine. 2013;59:45-55.

[7] Serhan CN, Chiang N, Van Dyke TE. Resolving inflammation: dual antiinflammatory and pro-resolution lipid mediators. Nature Reviews Immunology. 2008;8:349-361.

[8] Gao L, Yin H, Milne G, Porter N, Morrow J. Formation of F-ring isoprostane-like compounds (F-3-isoprostanes) in vivo from eicosapentaenoic acid. J Biol Chem. 2006;281:14092-14099.

[9] Ferreiro-Vera C, Maria Mata-Granados J, Priego-Capote F, Manuel Quesada-Gomez J, Dolores Luque de Castro M. Automated targeting analysis of eicosanoid inflammation biomarkers in human serum and in the exometabolome of stem cells by SPE-LC-MS/MS. Analytical and Bioanalytical Chemistry. 2011;399:1093-1103.

[10] Massaro M, Scoditti E, Carluccio MA, De Caterina R. Basic mechanisms behind the effects of n-3 fatty acids on cardiovascular disease. Prostaglandins Leukotrienes Essential Fatty Acids. 2008;79:109-115.

[11] Waddington E, Sienuarine K, Puddey I, Croft K. Identification and quantitation of unique fatty acid oxidation products in human atherosclerotic plaque using highperformance liquid chromatography. Anal Biochem. 2001;292:234-244.

[12] Kelly L, Grehan B, Della Chiesa A, O'Mara SM, Downer E, Sahyoun G, Massey KA, Nicolaou A, Lynch MA. The polyunsaturated fatty acids, EPA and DPA exert a protective effect in the hippocampus of the aged rat. Neurobiol Aging. 2011;32:2318.e1. 
[13] Lee CH. Resolvins as New Fascinating Drug Candidates for Inflammatory Diseases. Arch Pharm Res. 2012;35:3-7.

[14] Serhan CN, Gotlinger K, Hong S, Lu Y, Siegelman J, Baer T, Yang R, Colgan SP, Petasis NA. Anti-inflammatory actions of neuroprotectin D1/protectin D1 and its natural stereoisomers: Assignments of dihydroxy-containing docosatrienes. Journal of Immunology. 2006;176:1848-1859.

[15] Perez-Martinez P, Perez-Jimenez F, Lopez-Miranda J. n-3 PUFA and lipotoxicity. Biochimica Et Biophysica Acta-Molecular and Cell Biology of Lipids. 2010;1801:362366.

[16] Brahmbhatt V, Oliveira M, Briand M, Perrisseau G, Schmid VB, Destaillats F, Pace-Asciak C, Benyacoub J, Bosco N. Protective effects of dietary EPA and DHA on ischemia-reperfusion-induced intestinal stress. J Nutr Biochem. 2013;24:104-111.

[17] McDaniel JC, Massey K, Nicolaou A. Fish oil supplementation alters levels of lipid mediators of inflammation in microenvironment of acute human wounds. Wound Repair and Regeneration. 2011;19:189-200.

[18] Neilson AP, Djuric Z, Ren J, Hong YH, Sen A, Lager C, Jiang Y, Reuven S, Smith WL, Brenner DE. Effect of cyclooxygenase genotype and dietary fish oil on colonic eicosanoids in mice. J Nutr Biochem. 2012;23:966-976.

[19] Harris WS, Mozaffarian D, Lefevre M, Toner CD, Colombo J, Cunnane SC, Holden JM, Klurfeld DM, Morris MC, Whelan J. Towards Establishing Dietary Reference Intakes for Eicosapentaenoic and Docosahexaenoic Acids. J Nutr. 2009;139:804S-819S.

[20] Méndez L, Pazos M, Gallardo JM, Torres JL, Pérez-Jiménez J, Nogués R, Romeu M, Medina I. Reduced protein oxidation in Wistar rats supplemented with marine $\omega 3$ PUFAs. Free Radical Biology and Medicine. 2013;55:8-20.

[21] Chapman R, Mackay K. The Estimation of Peroxides in Fats and Oils by the Ferric Thiocyanate Method. Journal of the American Oil Chemists Society. 1949;26:360-363.

[22] Lepage G, Roy C. Direct Transesterification of all Classes of Lipids in a One-Step Reaction. J Lipid Res. 1986;27:114-120.

[23] Tsukamoto T, Sonenberg M. Catecholamine Regulation of Human-Erythrocyte Membrane-Protein Kinase. J Clin Invest. 1979;64:534-540.

[24] Puttmann M, Krug H, Vonochsenstein E, Kattermann R. Fast Hplc Determination of Serum-Free Fatty-Acids in the Picomole Range. Clin Chem. 1993;39:825-832.

[25] Kaluzny M, Duncan L, Merritt M, Epps D. Rapid Separation of Lipid Classes in High-Yield and Purity using Bonded Phase Columns. J Lipid Res. 1985;26:135-140.

[26] Bligh E, Dyer W. A Rapid Method of Total Lipid Extraction and Purification. Canadian Journal of Biochemistry and Physiology. 1959;37:911-917. 
[27] Warensjo E, Rosell M, Hellenius M, Vessby B, De Faire U, Riserus U. Associations between estimated fatty acid desaturase activities in serum lipids and adipose tissue in humans: links to obesity and insulin resistance. Lipids in Health and Disease. 2009;8:37.

[28] Dasilva G, Pazos M, Gallardo JM, Rodríguez I, Cela R, Medina I. Lipidomic analysis of polyunsaturated fatty acids and their oxygenated metabolites in plasma by solid-phase extraction followed by LC-MS. Analytical and Bioanalytical Chemistry. 2014;406:2827-2839.

[29] Laura Lluís, Núria Taltavull, Mònica Muñoz-Cortés, Vanesa Sánchez-Martos, Marta Romeu, Montse Giralt, Eunice Molinar-Toribio, Josep Lluís Torres, Jara PérezJiménez, Manuel Pazos, Lucía Méndez, José M Gallardo, Isabel Medina, M Rosa Nogués. Protective effect of the omega-3 polyunsaturated fatty acids: Eicosapentaenoic acid/Docosahexaenoic acid 1:1 ratio on cardiovascular disease risk markers in rats. Lipids in Health and Disease. 2013;12.

[30] Di Nunzio M, Valli V, Bordoni A. Pro- and anti-oxidant effects of polyunsaturated fatty acid supplementation in HepG2 cells. Prostaglandins Leukotrienes Essential Fatty Acids. 2011;85:121-127.

[31] Shearer GC, Harris WS, Pedersen TL, Newman JW. Detection of omega-3 oxylipins in human plasma and response to treatment with omega-3 acid ethyl esters. J Lipid Res. 2010;51:2074-2081.

[32] Frankel EN. Lipid Oxidation. West Ferry, Dundee, Scotland: The Oily Press LTD; 1998.

[33] Richard D, Kefi K, Barbe U, Bausero P, Visioli F. Polyunsaturated fatty acids as antioxidants. Pharmacological Research. 2008;57:451-455.

[34] Garrel C, Alessandri J, Guesnet P, Al-Gubory KH. Omega-3 fatty acids enhance mitochondrial superoxide dismutase activity in rat organs during post-natal development. Int J Biochem Cell Biol. 2012;44:123-131.

[35] Chapman C, Morgan L, Murphy M. Maternal and early dietary fatty acid intake: Changes in lipid metabolism and liver enzymes in adult rats. J Nutr. 2000;130:146-151.

[36] Bouwens M, van de Rest O, Dellschaft N, Bromhaar MG, de Groot LCPGM, Geleijnse JM, Muller M, Afman LA. Fish-oil supplementation induces antiinflammatory gene expression profiles in human blood mononuclear cells. Am J Clin Nutr. 2009;90:415-424.

[37] $\mathrm{Fu} \mathrm{Z}$, Sinclair A. Novel pathway of metabolism of alpha-linolenic acid in the guinea pig. Pediatr Res. 2000;47:414-417.

[38] Borazan A, Binici DN. Relationship between Insulin Resistance and Inflamation Markers in Hemodialysis Patients. Ren Fail. 2010;32:198-202. 
[39] Martins AR, Nachbar RT, Gorjao R, Vinolo MA, Festuccia WT, Lambertucci RH, Cury-Boaventura MF, Silveira LR, Curi R, Hirabara SM. Mechanisms underlying skeletal muscle insulin resistance induced by fatty acids: importance of the mitochondrial function. Lipids in Health and Disease. 2012;11:30.

[40] Oh DY, Talukdar S, Bae EJ, Imamura T, Morinaga H, Fan W, Li P, Lu WJ, Watkins SM, Olefsky JM. GPR120 Is an Omega-3 Fatty Acid Receptor Mediating Potent Anti-inflammatory and Insulin-Sensitizing Effects. Cell. 2010;142:687-698.

[41] Casas JP, Shah T, Hingorani AD, Danesh J, Pepys MB. C-reactive protein and coronary heart disease: a critical review. J Intern Med. 2008;264:295-314.

[42] Calviello G, Su H, Weylandt KH, Fasano E, Serini S, Cittadini A. Experimental evidence of omega-3 polyunsaturated fatty acid modulation of inflammatory cytokines and bioactive lipid mediators: their potential role in inflammatory, neurodegenerative, and neoplastic diseases. BioMed research international. 2013;2013:743171-743171.

[43] Aguilera A, Diaz G, Barcelata M, Guerrero O, Ros R. Effects of fish oil on hypertension, plasma lipids, and tumor necrosis factor-alpha in rats with sucroseinduced metabolic syndrome. J Nutr Biochem. 2004;15:350-357.

[44] Reinders I, Virtanen JK, Brouwer IA, Tuomainen T. Association of serum n-3 polyunsaturated fatty acids with C-reactive protein in men. Eur J Clin Nutr. 2012;66:736-741.

[45] Masoodi M, Mir AA, Petasis NA, Serhan CN, Nicolaou A. Simultaneous lipidomic analysis of three families of bioactive lipid mediators leukotrienes, resolvins, protectins and related hydroxy-fatty acids by liquid chromatography/electrospray ionisation tandem mass spectrometry. Rapid Communications in Mass Spectrometry. 2008;22:7583. 